\title{
Use of conventional PCR and smear microscopy to diagnose pulmonary tuberculosis in the Amazonian rainforest area
}

\author{
F. Carniel ${ }^{1}$, E.R. Dalla Costa ${ }^{2}$, G. Lima-Bello ${ }^{1}$, C. Martins ${ }^{1}$, L.C. Scherer ${ }^{1}$ and M.L. Rossetti ${ }^{1,2}$ \\ ${ }^{1}$ Universidade Luterana do Brasil, Canoas, RS, Brasil \\ ${ }^{2}$ Centro de Desenvolvimento Científico e Tecnológico, Fundação Estadual de Produção e Pesquisa em Saúde, \\ Porto Alegre, RS, Brasil
}

\begin{abstract}
The diagnostic usefulness of Ziehl-Neelsen (ZN)-stained sputum smears combined with conventional polymerase chain reaction (ZN/PCR) to amplify IS6110 region DNA extracted from ZN slides was evaluated. The objective was to verify if this association could improve tuberculosis (TB) diagnosis in patients at remote sites. The study was carried out in 89 patients with culture-confirmed pulmonary TB as defined by the Brazilian Manual for TB Treatment. The participants were recruited in a reference unit for TB treatment in Rondônia, a state in the Amazonian area in northern Brazil. ZN, PCR, and culture performed in the sputum samples from these patients were analyzed in different combinations (i.e., ZN plus PCR and ZN plus culture). The prevalence rates of pulmonary TB in these patients were 32.6 and $28.1 \%$ considering culture and ZN/PCR, respectively. The sensitivity and specificity of ZN/PCR were 86 and 93\%, respectively. ZN/PCR was able to detect more TB cases than ZN alone. This method could offer a new approach for accurate tuberculosis diagnosis, especially in remote regions of the world where culture is not available.
\end{abstract}

Key words: Tuberculosis; Diagnosis; PCR

\section{Introduction}

Microscopic analysis of Ziehl-Neelsen (ZN)-stained smear preparations and sputum culture are the gold standard methods for diagnosing pulmonary tuberculosis (TB) despite many advances in laboratory diagnostic techniques (1). Although it has a low sensitivity, the ZN technique remains the primary tool for detecting pulmonary TB (2). The sputum culture can delay diagnosis by 3-6 weeks and has a biosafety hazard (3). In addition, culture may give false-negative results in $10-20 \%$ of cases $(4,5)$. Despite these shortcomings, $\mathrm{ZN}$ is often employed in low-income countries because it is inexpensive and easy to perform (6). Culture is not common due to a lack of laboratory facilities, materials and trained professionals.

Recently, a number of articles described the detection of Mycobacterium tuberculosis DNA by polymerase chain reaction (PCR). The results are promising and suggest that this method may be useful, mainly as a support to traditional diagnostic methods $(7,8)$. These tests can be carried out with DNA from various clinical sources (9), including slides prepared for microscopy, $(10,11)$, which is very useful due to easy and safe sample transport. The application of molecular tests in routine diagnosis in patients with suspected TB can be a useful option, especially at sites with a poor biosafety infrastructure that are far from reference centers for which safe sample transport is a major challenge. For these reasons, DNA extracted from microscopy slides should be a useful alternative (10-12). However, molecular testing methods require further investigation, including costeffectiveness studies, before implementation.

The objective of this study was to compare the performance and effectiveness of PCR in association with ZN staining (ZN/PCR) using DNA extracted from slides prepared for microscopy to diagnose TB at a reference health unit for TB treatment in the Amazonian region of Brazil, a difficult to access region with high prevalence.

\section{Material and Methods}

\section{Study setting}

Rondônia is a northern Brazilian state located in the Amazonian rainforest that includes several designated indigenous areas. This state reported 467 new TB cases

Correspondence: M.L. Rossetti, Centro de Desenvolvimento Científico e Tecnológico, Fundação Estadual de Produção e Pesquisa em Saúde, Av. Ipiranga, 5400, 3ํandar, 90610-000 Porto Alegre, RS, Brasil. Fax: +55-51-3352-0336. E-mail: mrossett@terra.com.br 
in 2010, an incidence of 30/100,000 inhabitants (13). Porto Velho City, the state capital, reported an incidence of 58/100,000 inhabitants in 2010. In Ji-Paraná City, the second largest city in Rondônia, the TB incidence was 60/ 100,000 (14). In a study published in 2012, designated indigenous areas located in several cities within the State had an incidence of around $137 / 100,000$ (14). In this state, a significant obstacle to health care access is the huge distances between the reference center and small cities. In Rondônia state, LACEN (i.e., the State Central Laboratory) is the only laboratory that can perform culture assay diagnosis of TB, resulting in enormous delays in providing diagnoses to Health Care Units within the State. In this study, it was not possible to evaluate TB/human immunodeficiency (HIV) coinfection; these data were not available in the medical records as the resource-limited setting has not yet integrated HIV and TB care for coinfected patients.

\section{Study population}

This study was performed in a group of routine patients with suspected pulmonary TB on clinical evaluation at the Adolfo Rhol Health Care Unit in Ji-Paraná City, Rondônia State, Brazil, from August 1, 2011 to January 31, 2012. All patients with smear results and culture criteria as defined by the Brazilian Manual for TB Treatment (1) were included. All patients agreed to participate in the study by signing a written informed consent. Patients without culture results or an inconclusive outcome at the end of study were excluded from the analysis. Laboratory technicians who carried out molecular testing were blinded to the bacteriology results. Culture for mycobacteria and smear microscopy were carried out for all clinical samples. Positive culture results in at least one sample with biochemical identification is the gold standard for TB diagnosis.

\section{Design}

This was a cross-sectional study conducted to evaluate the performance of a single molecular test for pulmonary TB diagnosis.

\section{Eligible and ineligible patients}

Patients with suspected pulmonary TB who were at least 18 years old and visited the Adolfo Rhol Health Care Unit between August 1, 2011 and January 31, 2012 were eligible. Eligible patients reported a cough of more than 3-weeks duration. Patients who were receiving anti-TB treatment when asked to participate in the study were ineligible. Patients with HIV or patients with a previous TB history were not excluded. Patients were excluded from the study if any of the following conditions were met: 1) culture was contaminated, 2) expectorated sputum was not obtained, 3) laboratory or clinical data did not fulfill the pulmonary TB definition or 4) written informed consent was not obtained.

\section{Laboratory analyses}

The smears were performed and evaluated at the health care station in Ji-Paraná City, Rondônia state. Regardless of a positive or negative result, all samples were transported in appropriate conditions to the Molecular Biology Laboratory at ULBRA (Brazilian Lutheran University) in Canoas City, Rio Grande do Sul state, where the DNA extraction and PCR analysis were carried out. The M. tuberculosis culture was performed at LACEN, in Rondônia, located in Porto Velho City, the state capital. The evaluations were conducted in accordance with the Quality Assessment of Diagnostic Accuracy Studies (QUADAS) and the Standards for Reporting Studies of Diagnostic Accuracy (STARD) criteria. 1) The patients were representative of those who will receive the test in routine clinical care. 2) The culture for mycobacteria and smear microscopy were carried out for all clinical samples on the same day. 3) The gold standard and the other tests were performed in all samples. 4) All patients received the result of the gold standard test independent of the PCR result. 5) Laboratory technicians were blinded to the gold standard result of all samples. 6) Laboratory technicians were blinded to the PCR result of all samples. 7) The clinical data available to the laboratory were the same as those used in routine practice (15). The samples were decontaminated and cultured in accordance with Kudoh and Kudoh (16) and identified according to Kubica's method (17).

\section{DNA extraction}

M. tuberculosis DNA was extracted from sputum fixed in smear slides according to the method described by van der Zanden et al. (12) with some modifications. Briefly, ultrapure water was added to smear slides to facilitate sample release. The extracted material was transferred to a microtube containing 5\% Chelex medium. After cellular lysis, the material was centrifuged at $4000 \mathrm{~g}$ for $10 \mathrm{~min}$, and the supernatant was added to phenol-chloroform-isoamyl alcohol (24:24:1) solution to remove interfering agents. Isoamyl alcohol was used to precipitate DNA.

\section{In-house PCR}

DNA amplification was performed as described by Rossetti et al. (18). The PCR steps were: DNA denaturing at $94^{\circ} \mathrm{C}$ for $2 \mathrm{~min}$, primer annealing at $68^{\circ} \mathrm{C}$ for $2 \mathrm{~min}$, and extension at $72^{\circ} \mathrm{C}$ for $2 \mathrm{~min}$.

\section{Statistical analysis}

The collected data were analyzed by SPSS 16.0 (USA). The descriptive data analyses are reported as means $\pm S D$. The estimated sensitivity (SE) and specificity (SP) and their respective confidence intervals (Cls) were calculated (19). The Kappa coefficient $(\kappa)$ was used to verify the concordance between the proposed assay 
and smear and culture $(19,20)$. For the inferential analysis, the significance level was $5 \%$, and the positive and negative predictive (PPV and NPV) values were also calculated. Test performance was calculated using a specific formula utilized by parallel tests: sensitivity (SE) of ZN with culture: $\left(S_{z n}+S E_{\text {culture }}\right)-\left(S E_{z n} \times S E_{\text {culture }}\right)$, specificity (SP) of $\mathrm{ZN}$ with culture: $\mathrm{SP}_{\mathrm{zn}} \times \mathrm{SP}_{\text {culture, and }}$ predictive values (PV).

\section{Ethical aspects}

This study was approved by Ethics Committee of Centro Universitário Luterano, Ji-Paraná (No. 011/2011).

\section{Results}

A total of 89 patients with suspected pulmonary TB, 55 of whom were male, were enrolled in this study. The prevalence of pulmonary TB was $32.6 \%$ (29/89). Among these patients, $89(100 \%)$ had cough, $33(37.1 \%)$ experienced thoracic pain, $66(74.2 \%)$ had dyspnea, 21 (23.61\%) reported weight loss, $16(18 \%)$ had obstructive chronic pulmonary disease, $6(6.7 \%)$ were alcoholics, and $30(34.1 \%)$ had previous TB.

\section{Concordance analysis and methods performance}

Among the 89 analyzed samples $32.6 \%(29 / 89)$ had positive culture, $14(15.7 \%)$ had positive $\mathrm{ZN}$, and 25 $(28.1 \%)$ had positive PCR results (Table 1$)$. Nineteen samples $(21.3 \%)$ had divergent results, 15 (79\%) with positive culture and negative ZN were positive PCR in 8 cases and in $4(21 \%)$ cases despite negative culture and ZN, the PCR was positive (Table 1). Overall, PCR diagnosed 7 (24\%) more cases than ZN. The comparison between PCR and culture yielded a moderate $\kappa$ coefficient $(\kappa=0.68, P<0.01)$. The $\kappa$ for association between $Z N$ and culture was $\kappa=0.55(P<0.01)$, and that between ZN/PCR and culture was $\kappa=0.79(P<0.01)$. The concordance between $\mathrm{ZN}$ and PCR was weak but significant $(0.39$, $\mathrm{P}<0.01)$. The association of $\mathrm{ZN}$ plus $\mathrm{PCR}$ had $86 \%$ sensitivity, $93 \%$ specificity, and $91 \%$ accuracy. The results showed that $\mathrm{PCR}$ sensitivity was improved when combined with ZN. The specificity of the combined ZN/ PCR test was not affected, as shown in Table 1. This association was evaluated considering different TB prevalence scenarios to verify how the evaluated method would work in places with different prevalence rates. In regions with a TB prevalence of $10 \%$, which is often seen in TB ambulatory health care stations and in individuals with respiratory symptoms including a cough of more than 3 weeks duration, the NPV of the ZN/PCR method was $93 \%$. In hospitals or reference ambulatory centers for TB, places where the TB prevalence usually varies between $15 \%$ and $20 \%$, the PPV of this diagnostic strategy was $94 \%$. In reference hospitals for TB, where the TB prevalence range is $30 \%$ to $50 \%$, ZN/PCR strategy had a PPV range of $93 \%$ to $94 \%$.

\section{Discussion}

The World Health Organization (WHO) has been recommending the development and use of new, more sensitive, and simpler TB diagnostic tools as way to stop the spread of TB $(21,22)$. Researchers from around the world have been concentrating efforts on developing rapid, low-cost tests that can be used in remote places with limited resources, with the goal of decreasing the waiting time for TB diagnosis. In 2010, the WHO started recommending the GeneXpert for use in many countries due to its simplicity. However, its usage still needs studies of cost-effectiveness in developing countries like Brazil $(23,24)$. In the present report, we analyzed a conventional and simple PCR for routine TB diagnosis, aiming to evaluate its potential use at remote sites where there is a need to overcome the inherent limitations of traditional methods. PCR was performed with DNA extracted from ZN slides, which are easy and safe to transport because there is no contamination hazard. The IS6110 sequence was the PCR target that, in addition to detecting TB, distinguishes between $M$. tuberculosis and other mycobacteria. It is specific to the $M$. tuberculosis complex (MTBC) (25). In a study carried out in India by Negi et al. (26) that compared different PCR protocols targeting different $M$. tuberculosis gene sequences, PCR targeting IS6110 was found to have better positivity (77\%) than other molecular targets like $65 \mathrm{kDa}(75 \%), 38 \mathrm{kDa}(72 \%)$, and the $85 \mathrm{~B}$ protein (73\%). Among the samples with negative results provided by conventional tests, IS6110PCR showed greater positivity (26\%) than PCR carried out for other targets. The PCR targeting of IS6110 has been widely reported by various reference centers for TB diagnosis that reported that it was simple and reproducible $(8,27)$. In this study, we demonstrated that in-house PCR using DNA extracted from ZN slides is a feasible alternative for $M$. tuberculosis detection, with a decreased waiting time for results and an increased case detection rate. Of 29 PCR-positive samples, only 14 were ZN positive; this means that it was possible to obtain a TB diagnosis in only $48.2 \%$ of the studied samples by ZN, compared to $72.4 \%$ by ZN/PCR. The results thus show that ZN/PCR diagnosed seven (24.14\%) additional cases. This low ZN sensitivity in properly identifying TB suggests that a culture should be routinely performed for each suspected TB case; however, the waiting time, cost, and biosafety concerns limit its routine use.

PCR with DNA extracted from ZN slides could be a good diagnostic alternative for TB diagnosis by culture methods, and it could also be used to exclude a TB diagnosis. The statistical analysis revealed that ZN/PCR had a sensitivity of $86 \%$, a specificity of $93 \%$, an accuracy of $91 \%$, and a NPV value of $93 \%$, which confirms that combining these tests could be useful either for TB diagnosis or exclusion. In a similar study, Scherer et al. (28) evaluated the routine clinical use of PCR combined 
Table 1. Performance of the 3 methods (ZN, PCR and ZN/PCR).

\begin{tabular}{|c|c|c|c|c|c|}
\hline Laboratory results & Sample cultured $(n=89)$ & $\mathrm{ZN}$ & PCR & $\mathrm{ZN}$ & PCR \\
\hline & & \multicolumn{2}{|c|}{ Positive results } & \multicolumn{2}{|c|}{ Negative results } \\
\hline \multirow[t]{2}{*}{ Positive } & \multirow[t]{2}{*}{29} & 14 & 21 & 15 & 8 \\
\hline & & \multicolumn{2}{|c|}{ Negative results } & \multicolumn{2}{|c|}{ Positive results } \\
\hline Negative & 60 & 60 & 56 & 0 & 4 \\
\hline Methods & SE & SP & PPV & NPV & Accuracy \\
\hline \multirow[t]{2}{*}{ ZN } & $48 \%$ & $100 \%$ & $100 \%$ & $80 \%$ & 83 \\
\hline & $95 \% \mathrm{Cl}(38 ; 59)$ & $95 \% \mathrm{Cl}(100 ; 100)$ & & & $95 \% \mathrm{Cl}(75 ; 91)$ \\
\hline \multirow[t]{2}{*}{ PCR } & $72 \%$ & $93 \%$ & $84 \%$ & $87 \%$ & 86 \\
\hline & $95 \% \mathrm{Cl}(63 ; 82)$ & $95 \% \mathrm{Cl}(88 ; 98)$ & & & $95 \% \mathrm{Cl}(79 ; 94)$ \\
\hline \multirow[t]{2}{*}{ ZN/PCR } & $86 \%$ & $93 \%$ & $88 \%$ & $93 \%$ & 91 \\
\hline & $95 \% \mathrm{Cl}(79 ; 93)$ & $95 \% \mathrm{Cl}(88 ; 98)$ & & & $95 \% \mathrm{Cl}(85 ; 97)$ \\
\hline
\end{tabular}

ZN: Ziehl-Neelsen-stained sputum smears; PCR: polymerase chain reaction; SE: sensitivity; SP: specificity; PPV and NPV: positive and negative predictive value, respectively.

with ZN as an option for earlier diagnosis. They found that ZN/PCR had $92 \%$ sensitivity and $93 \%$ NPV. A study was also carried out in India with samples from patients with and without TB, and PCR showed a sensitivity of $84.61 \%$ and specificity of $80 \%$, significantly better than the methods of ZN alone and culture (29). In this study, the association of ZN/PCR had a sensitivity of $86 \%$, which could be explained by many factors, one being the presence of PCR inhibitors in the samples after the extraction process. A study performed in Morocco, a country with a high rate of TB, compared PCR with conventional methods and found that this test could detect $M$. tuberculosis with high sensitivity (98\%) and good specificity (92.6\%), and the concordance between PCR and culture was 0.9088 . This same study reported that false-negative results could be associated with either the paucibacillary nature of the sample, inefficient DNA extraction, or PCR inhibitors present in the sample (30). Assuming different scenarios of TB prevalence, ZN/PCR has shown good performance, with NPV and PPV that

\section{References}

1. Brasil. Ministério da Saúde. Programa nacional de controle da tuberculose. Manual de Recomendações para o Controle da Tuberculose no Brasil. 1st edn. Brasília: Secretaria de Vigilância em Saúde; 2011.

2. World Health Organization. WHO global report 2011. http:// www.who.int/tb/laboratory/en. Accessed October 31, 2013.

3. World Health Organization. Systematic screening for active tuberculosis. Principles and recommendations. http:// www.who.int/tb/tbscreening/en/. Accessed November 1, 2013.

4. Dye C, Scheele S, Dolin P, Pathania V, Raviglione MC. Consensus statement. Global burden of tuberculosis: estimated incidence, prevalence, and mortality by country. WHO Global Surveillance and Monitoring Project. JAMA range from $93-94 \%$ and $86-88 \%$, respectively, and significant changes with changes in TB prevalence. These data confirm that ZN/PCR could be considered as a method to exclude TB diagnoses in ambulatory care centers, reference centers, and hospitals. In a study reported by Scherer et al. (28), where the assumed prevalence ranged from 5-20\%, a high NPV was obtained. However, these numbers decreased in TB scenarios where the prevalence was higher than $30 \%$, especially among HIV-positive patients.

Our findings suggest that molecular diagnosis has a strategic potential in the fight against TB. The results demonstrated that ZN/PCR using DNA extracted from ZN-stained sputum-sample slides could be an alternative to diagnose pulmonary TB in remote areas. We found that this method had good sensitivity, specificity, NPV, and PPV. The application of ZN/PCR could decrease the waiting time for a pulmonary TB diagnosis, while simultaneously decreasing the biosafety hazard.
1999; 282: 677-686, doi: 10.1001/jama.282.7.677.

5. Pai M, Flores LL, Hubbard A, Riley LW, Colford JM Jr. Nucleic acid amplification tests in the diagnosis of tuberculous pleuritis: a systematic review and meta-analysis. BMC Infect Dis 2004; 4: 6, doi: 10.1186/1471-2334-4-6.

6. Kivihya-Ndugga L, van Cleeff M, Juma E, Kimwomi J, Githui $W$, Oskam L, et al. Comparison of PCR with the routine procedure for diagnosis of tuberculosis in a population with high prevalences of tuberculosis and human immunodeficiency virus. J Clin Microbiol 2004; 42: 1012-1015, doi: 10.1128/JCM.42.3.1012-1015.2004.

7. Weyer K, Carai S, Nunn P. Viewpoint TB diagnostics: what does the world really need? J Infect Dis 2011; 204 (Suppl 4): 
S1196-S1202, doi: 10.1093/infdis/jir452.

8. Michelon CT, Rosso F, Schmid KB, Sperhacke RD, Oliveira $\mathrm{MM}$, Kritski AL, et al. Colorimetric microwell plate reversehybridization assay for Mycobacterium tuberculosis detection. Mem Inst Oswaldo Cruz 2011; 106: 194-199, doi: 10.1590/S0074-02762011000200013.

9. Suffys P, Palomino JC, Cardoso LS, Espitia C, Cataldi A, Alito $A$, et al. Evaluation of the polymerase chain reaction for the detection of Mycobacterium tuberculosis. Int J Tuberc Lung Dis 2000; 4: 179-183.

10. van der Zanden AG, Hoentjen AH, Heilmann FG, Weltevreden EF, Schouls LM, van Embden JD. Simultaneous detection and strain differentiation of Mycobacterium tuberculosis complex in paraffin wax embedded tissues and in stained microscopic preparations. Mol Pathol 1998; 51: 209-214, doi: 10.1136/mp.51.4.209.

11. Fontes AN, Gomes HM, Araujo MI, Albuquerque EC, Baptista IM, Moura MM, et al. Genotyping of Mycobacterium leprae present on Ziehl-Neelsen-stained microscopic slides and in skin biopsy samples from leprosy patients in different geographic regions of Brazil. Mem Inst Oswaldo Cruz 2012; 107 Suppl 1: 143-149, doi: 10.1590/ S0074-02762012000900021.

12. van der Zanden AG, Te Koppele-Vije EM, Vijaya Bhanu N, Van Soolingen D, Schouls LM. Use of DNA extracts from Ziehl-Neelsen-stained slides for molecular detection of rifampin resistance and spoligotyping of Mycobacterium tuberculosis. J Clin Microbiol 2003; 41: 1101-1108, doi: 10.1128/JCM.41.3.1101-1108.2003.

13. Brasil. Ministério da Saúde do Brasil. Secretaria de Vigilância em Saúde. Sistema de informação de agravos de notificação SINAN. Brasília: Departamento de Vigilância Epidemiológica; 2012.

14. Melo TE, Resendes AP, Souza-Santos R, Basta PC. [Spatial and temporal distribution of tuberculosis in indigenous and non-indigenous of Rondonia State, Western Amazon, Brazil]. Cad Saude Publica 2012; 28: 267-280, doi: 10.1590/S0102-311X2012000200006.

15. Oliveira MR, Gomes AC, Toscano CM. QUADAS and STARD: evaluating the quality of diagnostic accuracy studies. Rev Saude Publica 2011; 45: 416-422, doi: 10.1590/S0034-89102011000200021.

16. Kudoh S, Kudoh T. A simple technique for culturing tubercle bacilli. Bull World Health Organ 1974; 51: 71-82.

17. Kent PT, Kubica GP. Public health mycobacteriology - a guide for level III laboratory. Atlanta: U.S. Dept. of Health and Human Services, Public Health Service, Centers for Disease Control; 1985.

18. Rossetti MLR, Sperhacke RD. Tuberculose. In: Rossetti MLR, Silva CMD, Rodrigues J (Editors), Doenças infecciosas: Diagnóstico molecular. 1st edn. Rio de Janeiro:
Guanabara Koogan; 2006. p 47-59.

19. Lwanga SK, Lemeshow S. Sample size determination in health studies: a practical manual. Geneva: World Health Organization; 1991.

20. Siegel S, Castellan NJ. Nonparametric statistics. 2nd edn. New York: McGraw-Hill; 1988.

21. WHO. The global plan to stop TB 2011-2015. Geneva: World Health Organization; 2010.

22. Updated guidelines for the use of nucleic acid amplification tests in the diagnosis of tuberculosis. MMWR Morb Mortal Wkly Rep 2009; 58: 7-10.

23. Machado AC, Steffen RE, Oxlade O, Menzies D, Kritski A, Trajman A. Factors associated with delayed diagnosis of pulmonary tuberculosis in the state of Rio de Janeiro, Brazil. J Bras Pneumol 2011; 37: 512-520, doi: 10.1590/S180637132011000400014

24. Steingart KR, Sohn H, Schiller I, Kloda LA, Boehme CC, Pai $M$, et al. Xpert(R) MTB/RIF assay for pulmonary tuberculosis and rifampicin resistance in adults. Cochrane Database Syst Rev 2013; 1: CD009593.

25. van Embden JD, Cave MD, Crawford JT, Dale JW, Eisenach KD, Gicquel B, et al. Strain identification of Mycobacterium tuberculosis by DNA fingerprinting: recommendations for a standardized methodology. J Clin Microbiol 1993; 31: 406-409.

26. Negi SS, Anand R, Pasha ST, Gupta S, Basir SF, Khare S, et al. Diagnostic potential of IS6110, $38 \mathrm{kDa}, 65 \mathrm{kDa}$ and 85B sequence-based polymerase chain reaction in the diagnosis of Mycobacterium tuberculosis in clinical samples. Indian J Med Microbiol 2007; 25: 43-49, doi: 10.4103/02550857.31061.

27. Flores LL, Pai M, Colford JM Jr, Riley LW. In-house nucleic acid amplification tests for the detection of Mycobacterium tuberculosis in sputum specimens: meta-analysis and metaregression. BMC Microbiol 2005; 5: 55, doi: 10.1186/14712180-5-55.

28. Scherer LC, Sperhacke RD, Jarczewski C, Cafrune PI, Michelon CT, Rupenthal R, et al. Comparison of two laboratory-developed PCR methods for the diagnosis of pulmonary tuberculosis in Brazilian patients with and without HIV infection. BMC Pulm Med 2011; 11: 15, doi: 10.1186/14 71-2466-11-15.

29. Mehta PK, Raj A, Singh N, Khuller GK. Diagnosis of extrapulmonary tuberculosis by PCR. FEMS Immunol Med Microbiol 2012; 66: 20-36, doi: 10.1111/j.1574-695X.2012. 00987.x.

30. Zakham F, Lahlou O, Akrim M, Bouklata N, Jaouhari S, Sadki K, et al. Comparison of a DNA based PCR approach with conventional methods for the detection of Mycobacterium tuberculosis in Morocco. Mediterr $J$ Hematol Infect Dis 2012; 4: e2012049. 